\title{
Leprosy in a University Hospital in Southern Brazil ${ }^{*}$
}

\author{
Adma Silva de Lima ${ }^{1}$ \\ Míryan Priscilla Santos Bona ${ }^{3}$ \\ Marina Portiolli Hoffmann ${ }^{3}$ \\ Vanessa Cristhine Dallolmo Ottoboni ${ }^{3}$
}

\author{
Karin Cristine Pinto ${ }^{2}$ \\ Suelen Mayara Lopes de Mattos ${ }^{3}$ \\ Fabiane Andrade Mulinari-Brenner ${ }^{3}$
}

DOI: http://dx.doi.org/10.1590/abd1806-4841.20153959

\begin{abstract}
BACKGROUND: Leprosy is an infectious disease that may lead to irreversible nerve damage, compromising patient's quality of life and leading to loss of working years.

OвJестіVEs: To evaluate the epidemiological profile of patients followed at a University Hospital.

Materials And Methods: This is a retrospective observational study, based on a review of medical records. We studied the clinical and epidemiological features of patients with leprosy monitored at the Hospital de Clínicas of the Federal University of Paraná between January 2005 and January 2010.

RESUlTs: The mean age was 47.51, while 35.94\% of patients were aged 41-60. The male:female rate was 1.8:1. The most prevalent occupations were: retired, students or rural workers. Patients came mainly from Curitiba or nearby areas, but there were also patients from the countryside. The mean diagnostic delay was 24.57 months. Multibacillary forms prevailed, with the lepromatous variety being the most common, closely followed by the borderline type. Neural enlargement was found in more than 50\% of the patients and $48.44 \%$ of them developed reactional states. Hemolysis was the most commonly detected drug side effect. Initial functional evaluation was possible in $70 \%$ of patients, $55 \%$ of whom had disabilities upon diagnosis. The most prevalent associated disease was hypertension.

CONCLUSIONS: This study showed an important diagnostic delay and a high rate of sequelae in this specific population. Brazil is one of the few remaining countries that has not yet eradicated leprosy and it is important to improve health policies in order to prevent sequelae and achieve eradication.
\end{abstract}

Keywords: Leprosy; Leprosy, borderline; Leprosy, lepromatous; Leprosy, multibacillary; Leprosy, paucibacillary; Leprosy, tuberculoid; Mycobacterium leprae

\section{INTRODUCTION}

Leprosy is an infectious disease caused by Mycobacterium leprae, also known as Hansen's bacilli (HB) ${ }^{1,2}$, an alcohol-acid resistant bacilli, first described by Amauer Hansen in $1873^{2}$. Brazil has the world's second highest number of cases, just below India. ${ }^{1-5}$

Hansen's bacilli have high infectivity rates but low pathogenicity. ${ }^{5}$ Over $95 \%$ of people are naturally resistant to the disease ${ }^{4}$. Although $\mathrm{HB}$ may be encountered in wild animals, it is generally accepted that men are responsible for transmission. ${ }^{3}$
Inhaled respiratory droplets are accepted as the source of infection, although eroded skin can be a point of entry for the bacilli ${ }^{3}$. Genetic and environmental features are essential for the disease's development. ${ }^{6}$ Differences in immune responses lead to variable clinical forms and account for reactional states. ${ }^{3,5}$ Depending on T-cell activity towards the bacilli, the defense may be effective or allow the dissemination of the microorganism.

Received on 18.08.2014.

Approved by the Advisory Board and accepted for publication on 14.10.2014

Work performed at the Hospital de Clínicas da Universidade Federal do Paraná (HC-UFPR) - Curitiba (PR), Brazil.

Financial Support: None.

Conflict of Interest: None.

Private Clinic - Brusque (SC), Brazil.

Irmandade da Santa Casa de Misericórdia de São Paulo - São Paulo (SP), Brazil.

Universidade Federal do Paraná. Curitiba (UFPR) - Curitiba (PR), Brazil.

(C2015 by Anais Brasileiros de Dermatologia 
In 1991, the World Health Organization (WHO) launched a world campaign to eliminate the public health problem of leprosy by the year 2000. Elimination means prevalence of less than 1 case/10,000 inhabitants. ${ }^{7}$ Nevertheless, by 2000, 24 countries had not achieved this goal, including Brazil. Although elimination targets were not met, Brazil nonetheless saw a significant decrease in prevalence rates, down from 16.4 cases/10,000 inhabitants in 1985 to 1.5 cases $/ 10,000$ inhabitants in $2005 .^{5}$

Cases are not distributed homogeneously across Brazil. The north and northeast of the country have the highest prevalence and incidence rates, while southern states have already achieved eradication levels. ${ }^{8}$

This study aimed to establish the clinical and epidemiological profile of leprosy patients at a university hospital in Curitiba, southern Brazil - Hospital de Clínicas of the Federal University of Paraná, a referral center for complicated cases. As Brazil is one of the last endemic countries for leprosy, the present study may help to understand how control measures operate shall improve around the globe.

\section{MATERIALS AND METHODS}

This is a descriptive, retrospective, crosssectional study based on data collected from patient files analyzed at the Hospital de Clínicas of the Federal University of Paraná between January 2005 and January 2010. It was approved by the Ethical and Research Committee.

The study applied the following inclusion criteria: patients treated and/or accompanied at the leprosy clinic of the hospital's dermatology department between January 2005 and January 2010, and/or examined at other clinics and notified to the hospital's epidemiology service. It also included patients who had previously been treated and referred because of reactions or diagnostic doubts. The study excluded patients whose diagnose was not confirmed or ruled out during follow-up, in addition to those who initiated treatment before January 2005 or had not finished by January 2010.

The following clinical and epidemiological data were collected: age, profession, educational level, initial and final bacilloscopic index, glucose-6phosphatedehydrogenase deficiency screening, clinical form of the disease, treatment type and duration, delay in diagnosis, leprosy reactions, complications, sequelae, initial and final functional evaluation and comorbidities. Furthermore, a statistician performed basic statistical analyses of mean and median ages, and the frequency of the most important clinical characteristics.

Some of our data were also compared with data from the Notifiable Diseases Information Center at the Brazilian Ministry of Health (SINAN) [Available at: http://dtr2004.saude.gov.br/sinanweb/tabnet/ tabnet?sinannet/hanseniase/bases/Hansbrnet.def]

\section{RESULTS}

Eighty-one patients were examined in Dermatology's Leprosy outpatient clinic during the period. Sixty-four were eligible for this study. Among these cases, the mean age was 47.51 years. Fifteen patients were younger than $20(7.81 \%)$, twenty (31.25\%) were aged $20-40$, twenty-three (35.94\%) were aged $41-60$, while sixteen patients $(25 \%)$ were aged over 60 (Graph 1). According to SINAN, during this period, a total of 9.169 cases were reported across the state, involving mostly people aged over 15 .

Men accounted for $64.06 \%$ of cases while women represented $35.94 \%$.

We noted the occupations of sixty-one individuals out of sixty-four. Patients were mainly retired $(14 \%)$, followed by housewives (12.5\%), students $(7.81 \%)$ and rural workers $(6.35 \%)$. The time from the beginning of the symptoms until diagnosis (not treatment) represented the delay in diagnosis. The mean delay was 24.57 months. Most patients were diagnosed in the first year of disease, though some patients had had it for over three years, increasing the mean delay rate (Graph 2).

Multibacillary forms were more common. Lepromatous leprosy accounted for $35.93 \%$ of the cases followed by borderline forms (34.39\%) (Graph 3). This data agree with the SINAN state database, which showed that lepromatous leprosy accounted for most

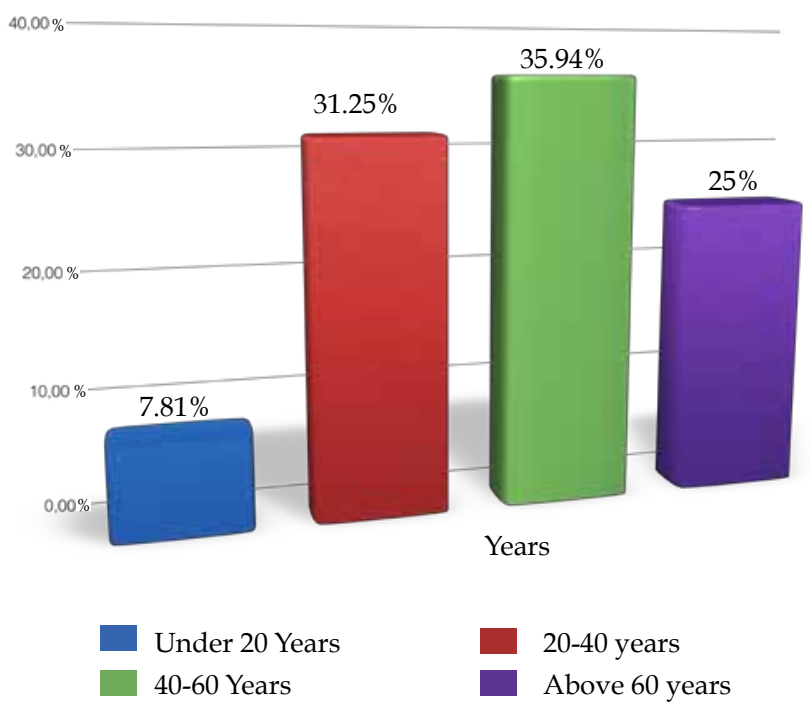

Graph 1: Age range of patients, showing that the disease is more prevalent during their working years 


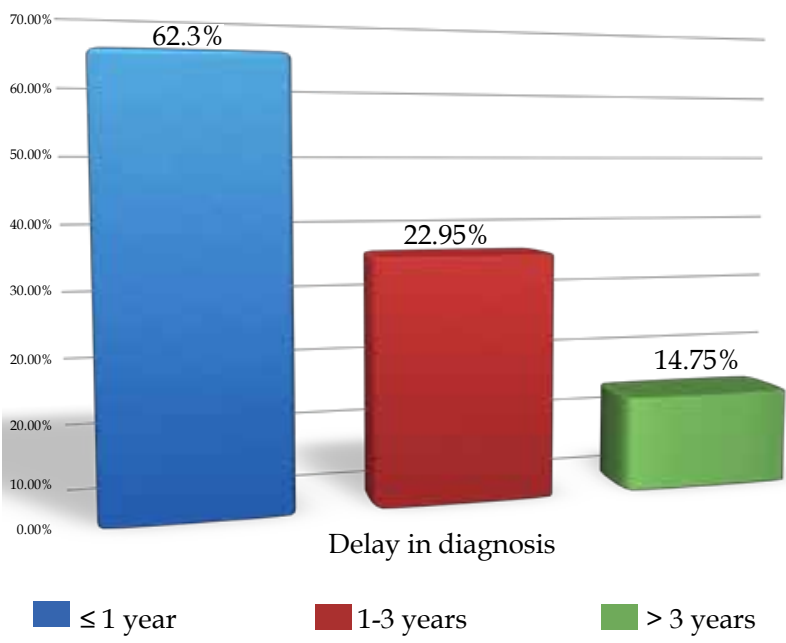

Graph 2: Delay in Diagnosis. Delay in Diagnosis in years

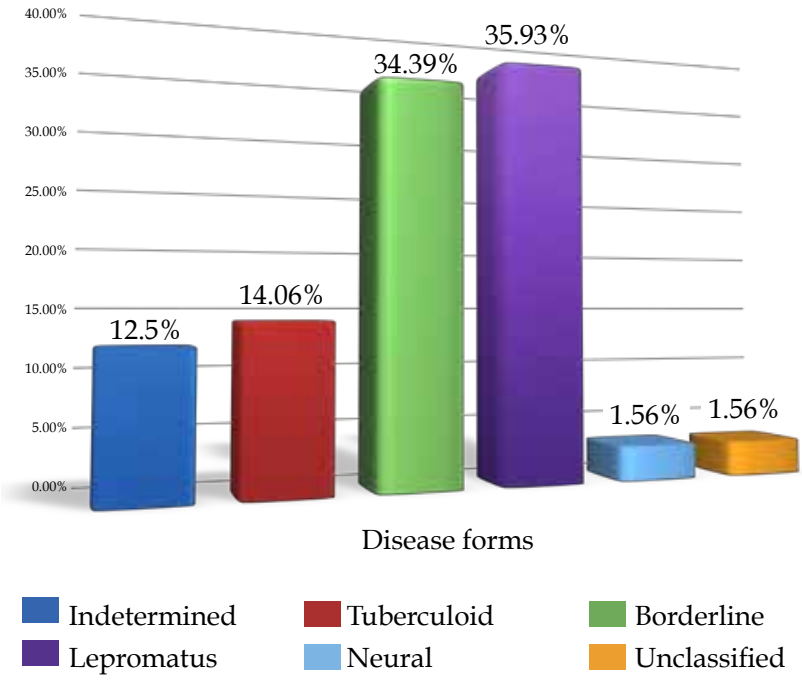

Graph 3: Disease Forms. Disease Forms showing that multibacillary forms were more common

cases $(34 \%)$, followed by the borderline form $(22.63 \%)$.

Neural thickening was detected in $57.81 \%$ of patients during clinical examination. The ulnar nerve was the most commonly affected (51.56\% of the cases), followed by the tibial, fibular (peroneal) and great auricular nerves, with $6.25 \%$ each (Graph 4 ).

Most of the patients were treated for multibacillary forms: lepromatous or borderline varieties. The most commom side effect was hemolysis due to dapsone intake, which was observed even in patients who did not have glucose-6-phosphate dehydrogenase deficiency. Concomitant infections, such as herpes zoster, tuberculosis and pneumonia, were also detected. Nasal miiasis was found in one patient, who required hospitalization for adequate

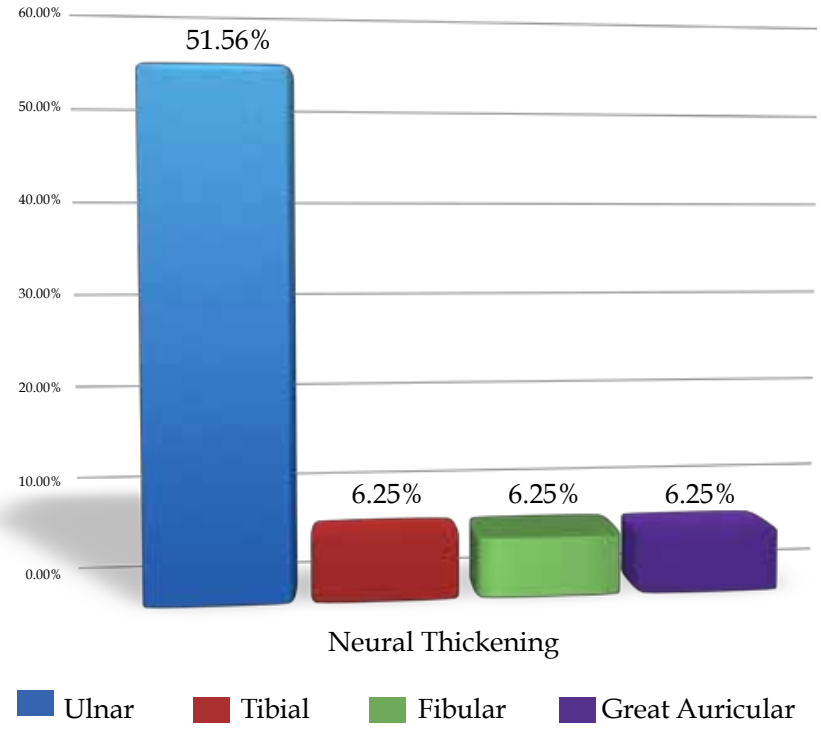

GrapH 4: Neural Thickening. Neural Thickening frequency, showing that the ulnar nerve was the most commonly affected

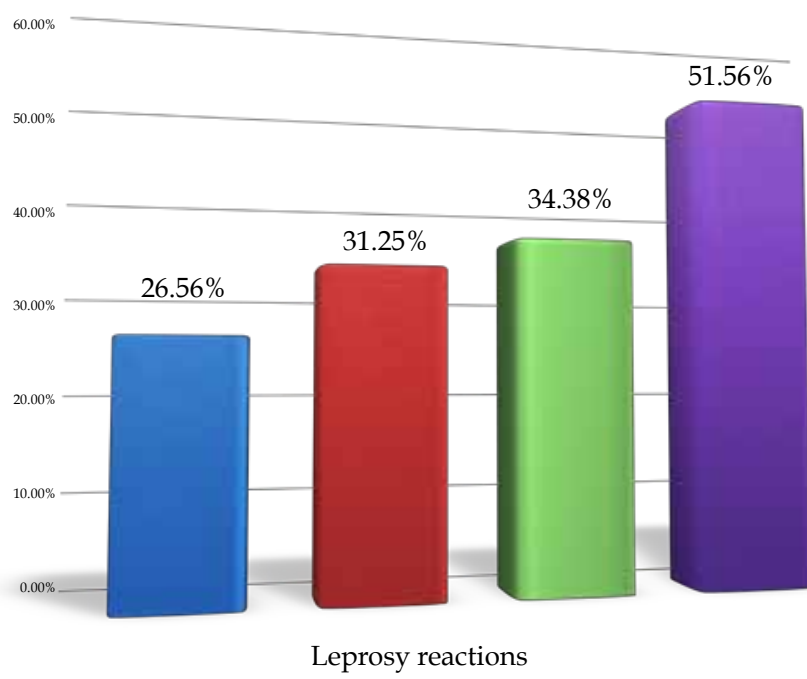

Type $1 \square$ Type $2 \square$ Neurites $\quad$ No reactions

GrAPH 5: Leprosy reactions. Leprosy reactions including neuritis, either isolated or associated with other disease forms

treatment. Neurological complications included stroke in one patient and psicosis in another, due to corticosteroid usage to treat leprosy reactions.

Many patients developed leprosy reactions during treatment and follow-up (48.44\% of cases). Neuritis was the most common reaction (34.38\%), either with or without other reactions, followed by type $2(31.25 \%)$ and type 1 (26.56\%) reactions (Graph 5). 
Functional evaluation is a tool for screening disabilities, performed upon diagnosis and after treatment. Initial functional evaluation was possible in $70 \%$ of patients, $55.55 \%$ of whom presented some degree of disability (functional evaluation grades 1 or 2) at the diagnosis (Graph 6). These data contrast with data from the SINAN database, which showed that the majority of patients had no disabilities at the diagnosis (54\%), while $38 \%$ had functional evaluation grades 1 and 2.

Comorbidities were also evaluated. The most frequent condition was hypertension ( $25 \%$ of cases).

\section{DISCUSSION}

According to the SINAN notification system, 9.169 leprosy cases were notified and confirmed in the state between 2005 and 2010. Eighty-one cases were evaluated at this service, representing $0.8 \%$ of all cases across the state.

The mean age of patents was 47.51 and most were aged 41-60. These data are in line with another study from Santa Catarina, a neighbor state in southern Brazil. ${ }^{9}$ Nevertheless, studies from other Brazilian states have found greater prevalence in younger patients. ${ }^{10,11,12}$

Further, this study also uncovered a higher prevalencein men, in accordance with the state's medical literature and data from the same period. ${ }^{4,10,12,13}$ The proportion between males and females was 1.8:1.

Delay in diagnosis is a major problem in Brazil and other endemic countries. The definition of delay also varies across studies. Here, delay denotes the time from the beggining of symptoms until diagnosis,

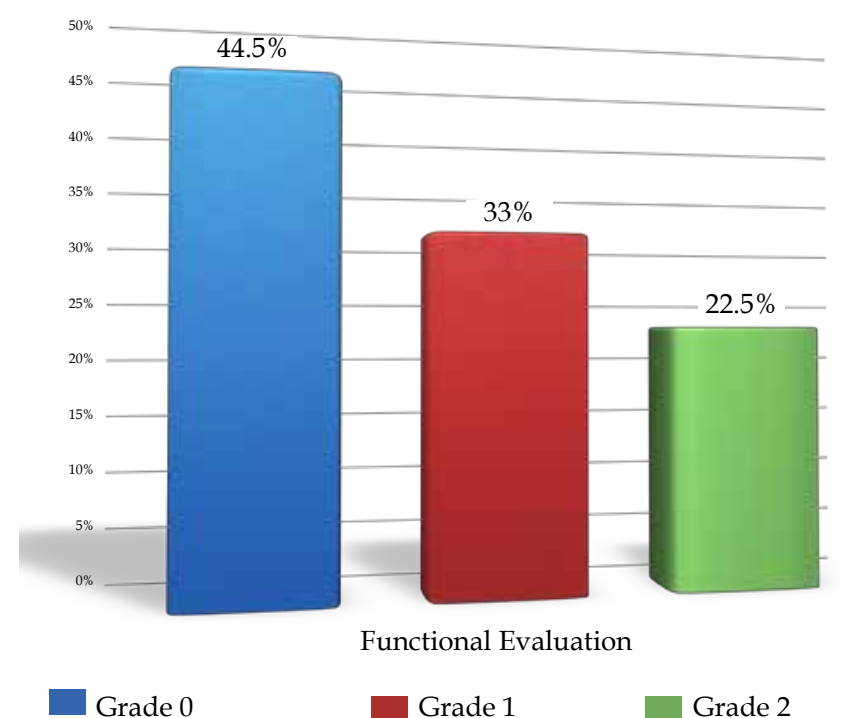

Graph 6: Functional Evaluation. Functional evaluation showing that patients still arrive at hospitals with disabilities while other studies consider it to end only when treatment begins. ${ }^{14}$ In this study, the mean delay was 24.57 months, just over 2 years. Most patients were diagnosed during the first year of the disease $(62.3 \%)$; nevertheless, some patients took up to 12 years to be diagnosed, which ultimately increased the mean delay. There was no difference in delay among the clinical forms of the disease. Similar results were obtained by Deps et al. ${ }^{14}$. Studying the metropolitan area of Vitoria, in southwestern Brazil, they noted a mean diagnosis delay of 25.25 months. They also found this delay to be greater in multibacillary patients. Some authors suggest that a delay longer than 6 months might be hazardhous to both the patient and the economy. Delay in diagnosis may lead to greater neural damage and deformities. In Brazil and other developing countries, access to public health services can be difficult. Leprosy patients can wait more than a year to receive specialized evaluation, thus impairing prognosis. In addition, physicians may face difficulties in making the diagnosis at a primary care institution. Lastoria et al. ${ }^{2}$ found that delays in diagnosis were due to the difficulties patients had in reaching health centers, as well as the fact that most were examined at two services (at least) before leprosy was diagnosed. ${ }^{2}$

Most patients in our study were multibacillary: $35.93 \%$ presented with the lepromatous form, while $34.39 \%$ had the borderline variety, representing $70.32 \%$ of the cases. These data agree with state data from the same period. Other Brazilian studies have shown discrepant results. Lima et al. ${ }^{10}$ found the tuberculoid form to be the most prevalent in Federal District between 2000 and 2005. This clinical form prevails in endemic areas and its expansion seems to correlate with the disease's expansion. Nonetheless, in a study conducted in Santa Catarina between 1999 and 2003, Melo et al. ${ }^{9}$ observed a low prevalence of the tuberculoid form (about 5.5\% of cases). Some authors also found that multibacillary forms prevailed in their areas. ${ }^{13}$ In Prudentópolis, another city in the state of Paraná, $63 \%$ of the new cases were multibacillary, with most cases involving lepromatous patients ${ }^{4}$. Their data were similar to those in this study, representing a further sample from the same state. Furthermore, after studying cases from a leprosy referral center in Maranhão (northeastern Brazil), Corrêa et al. ${ }^{13}$ uncovered a higher prevalence of multibacillary forms, the most commonly detected of which was the lepromatous variety, thus agreeing with the present study, also conducted at a referral center.

The lepromatous form is particularly common in elderly and middle-aged patients. The deficit caused by immune senescence may be related to the increased prevalence of these forms at older ages. The presence of older patients in the sample may also reflect their 
prevalence in this study.

Thickening of nerve trunks on physical examination was detected in most patients, notably the ulnar nerve (over 50\%). Changes in the greater auricular, tibial and fibular nerves were also detected in a lower percentage of patients, as observed in a previous Brazilian study ${ }^{15}$. Inspection of these nerve trunks should be emphasized at the initial physical examination of leprosy patients, due to the high rates of disease.

Leprosy reactions affected $48.44 \%$ of patients out of the full sample. Reaction rates vary greatly according to different studies worldwide. ${ }^{16}$ Type 1 reactions occur in approximately $20-30 \%$ of leprosy patients, while type 2 reactions show a wide geographic variation and appear mostly in multibacillary cases, affecting $20-37 \%$ of patients. In our study, neuritis was the most commonly detected reaction, afflicting over $34 \%$ of patients with or without type 1 or type 2 reactions. In our study, type 2 reaction was observed in $31.25 \%$ of patients, characterized by the appearance of Erythema Nodosum Leprosum, orchitis, hand and foot reaction, fever, lymphadenopathy, ocular manifestations, amongst other symptoms. Meanwhile, type 1 reaction was rarer, affecting 28.13\% of the sample. In a previous study conducted at this center, only $8.6 \%$ of patients presented leprosy reactions, with a predominance of type 1 reaction. ${ }^{17}$ The low number of patients with reactions during the period may be attributable to the fact that the service was not a referral center for leprosy treatment in the state at the time, and that patients were systematically referred to other clinics for treatment.

According to the Brazilian Ministry of Health, disabilities in leprosy are classified into grades 0-2: grade 0 signifies no disability in the eyes, hands or feet; level 1 denotes a decrease or loss of sensitivity in the eyes, hands and feet; grade 2 means disability and deformity. ${ }^{18}$ Patients are classified according to the worst criteria. In this study, the first functional evaluation was performed in $70 \%$ of patients. Most of the individuals studied had some degree of disability at diagnosis: $55.55 \%$ carried grade 1 and 2 disabilities, while $44.45 \%$ had no detectable disabilities. Most patients presented with grade 1 disabilities (33\%). These data contrast with data on the state from the same period, which showed that $54 \%$ patients had no disabilities at the diagnosis, while $38 \%$ carried some degree of functional impairment. The cases that reached the hospital may have been more aggressive and have entailed more disabilities. In another study, drawing on a sample of 79 patients, Gommes et al. ${ }^{19}$ detected that $38 \%$ had grade 2 disabilities and $26.6 \%$ were classed as grades 0 and 1 , respectively. The authors claim that disability degree is related to the presence of ulceration, which can cause serious damage to patients' health.

In their study, Gommes et al. ${ }^{19}$ found that hypertension was the most prevalent comorbidity, with diabetes mellitus ranked second, followed by other cardiovascular diseases. They reported a higher prevalence of hypertension..$^{19}$ It is a common condition among the population, with studies showing prevalence rates of around $20 \%$, which is coincident with the results of this study. ${ }^{20}$ Prevalence is probably related to the age at which the population is studied, rather than being a direct effect of the disease.

\section{CONCLUSION}

In the population studied, multibacillary forms prevailed and the rates of leprosy reactions were high. There was a mean delay in diagnosis of more than two years and disability rates were significant, with over $50 \%$ of the patients presenting with some degree of disability at the diagnosis.

Leprosy is a complex disease and still represents a major public health problem in Brazil, affecting many subjects in their working years, leading to disabilities. The epidemiological characteristics of leprosy in the referral centers may help to identify the population at risk of sequelae and leprosy reactions, which will enhance understanding of the disease and help to improve its management. [ 


\section{REFERENCES}

1. Kerr-Pontes LR, Barreto ML, Evangelista CM, Rodrigues LC, Heukelbach J, Feldmeier $\mathrm{H}$. Socioeconomic, environmental, and behavioural risk factors for leprosy in North-east Brazil: results of a case-control study. Int J Epidemiol. 2006;35:994-1000.

2. Lastória JC, Macharelli CA, Putinatti MSMA. Hanseníase: realidade no seu diagnóstico clínico. Hansen Int. 2003;28:53-8.

3. Araújo M. Hanseníase no Brasil. Rev Soc Bras Med Tropical 2003;36:373-82.

4. Sanches LA, Pittner E, Sanches HF, Monteiro MC. Detection of new cases of leprosy in the City of Prudentopolis, PR: the analysis from 1998 to 2005. Rev Soc Bras Med Trop. 2007 Sep-0ct;40(5):541-5.

5. Penna G0, Pinheiro AM, Nogueira LS, Carvalho LR, Oliveira MB, Carreiro VP. Clinical and epidemiological study of leprosy cases in the University Hospital of Brasilia: 20 years -- 1985 to 2005. Rev Soc Bras Med Trop. 2008;41:575-80.

6. Mendonça VA, Costa RD, Melo GEBA, Antunes CM, Teixeira AL. Immunology of leprosy. An Bras Dermatol. 2008;83:343-50

7. Lockwood DN1, Suneetha S. Leprosy: too complex a disease for a simple elimination aradigm. Bull World Health Organ. 2005;83:230-5.

8. Moreira MV, Waldman EA, Martins CL. Hanseníase no estado do Espírito Santo, Brasil: uma endemia em ascensão? Cad Saúde Pública. 2008;24:1619-30

9. Mello RS, Popoaski MCP, Nunes DH. Perfil dos pacientes portadores de Hanseníase na Região Sul do Estado de Santa Catarina no período de 01 de janeiro de 1999 a de dezembro de 2003. Arq Catarinenses Med. 2006;35:29-36.

10. Lima MAR, Prata MO, Moreira D. A description of Hansen's disease in the Brazilian Federal District from 2000 to 2005. Com Ciências Saúde. 2008;19:163-70.

11. Melão S, Blanco LF, Mounzer N, Veronezi CC, Simões PW. Epidemiological profile of leprosy patients in the extreme south of Santa Catarina between 2001 and 2007. Rev Soc Bras Med Trop. 2011;44:79-84.

12. Miranzi Sde S, Pereira LH, Nunes AA. Perfil epidemiológico da hanseníase em um município brasileiro, no período de 2000 a 2006. Rev Soc Bras Med Trop. 2010;43:62-7.

13. Corrêa Rda G, Aquino DM, Caldas Ade J, Amaral DK, França FS, Mesquita ER. Epidemiological, clinical, and operational aspects of leprosy patients assisted at a referral service in the state of Maranhão, Brazil. Rev Soc Bras Med Trop. 2012;45:89-94.

14. Deps PD, Guedes BV, Bucker Filho J, Andreatta MK, Marcari RS, Rodrigues LC. Delay in the diagnosis of leprosy in the metropolitan region of Vitoria, Brazil. Lepr Rev. 2006;77:41-7.

15. Pimentel MIF, Nery JAC, Borges E, Gonçalves RR, Sarno EM. Initial neurological exam of multibacillary leprosy: correlation between the presence of affected nerves and disability present at diagnosis and with the occurrence of overt neuritis. An Bras Dermatol. 2003;78:561-8.

16. Kahawita IP, Walker SL, Lockwood DNJ. Leprosy type 1 reactions and erythema nodosum leprosum. An Bras Dermatol. 2008;83:75-82

17. Mulinari-Brenner FA, Purin KSM, Santamaria JR, Pizzol AS, Manfrinato LC, Melo LMF, Mukai MM, Auada MP. Hanseníase em Hospital Escola. In: Anais do 53. Congresso Brasileiro de Dermatologia; 1998 Set 5-9; Blumenau. Blumenau: Sociedade Brasileira de Dermatologia; 1998.
18. bvsms.saude.gov.br [Internet]. Brasil. Ministério da Saúde. Secretaria de Políticas de Saúde. Departamento de Atenção Básica. Guia para o Controle da hanseníase. Brasília: Ministério da Saúde, 2002. [acesso 16 Fev 2014]. Disponível em: http://bvsms.saude.gov.br/bvs/publicacoes/guia_de_hanseniase.pdf. Acessed 2/16/2014.

19. Gomes FG, Frade MAC, Foss NT. Skin ulcers in leprosy: clinical and epidemiological characteristics of patients. An Bras Dermatol. 2007;82:433-7.

20. Passos VMA, Assis TD et Barreto SM. Hipertensão arterial no Brasil: estimativa de prevalência a partir de estudos de base populacional. Epidemiol Serv Saúde.2006;15:35-45

\author{
MAILING ADDRESS: \\ Adma Silva de Lima \\ Av. Augusto Bauer, 240 sala 502 \\ Jardim Maluche \\ 88354-040 - Brusque - SC \\ Brazil \\ E-mail:adma_lima@ibest.com.br
}

How to cite this article: de Lima AS, Pinto KC, Bona MPS, Mattos SML, Hoffmann MP, Mulinari-Brenner FA, Ottoboni VCD. Leprosy in a University Hospital in a Souther State of Brazil. An Bras Dermatol. 2015;90(5):654-9. 